\title{
Intraoperative Fracture of the Femur in Revision Total Hip Arthroplasty with a Fully HA-Coated Stem
}

\author{
David E. Rothem ${ }^{1,2,3^{*}}$, Lilah Rothem ${ }^{1}$, Alexander Lerner ${ }^{2,3}$, Tal Salamon ${ }^{2,3}$, Richard Hiscock ${ }^{1}$, \\ Neil Bergman ${ }^{1}$ \\ ${ }^{1}$ Warringal Private Hospital, Heidelberg, Australia \\ ${ }^{2}$ Ziv Medical Center, Zefad, Israel \\ ${ }^{3}$ Faculty of Medicine in the Galilee, Bar-Ilan University, Ramat Gan, Israel \\ Email: davidrothem@gmail.com
}

Received 9 February 2014; revised 10 March 2014; accepted 17 March 2014

Copyright (C) 2014 by authors and Scientific Research Publishing Inc.

This work is licensed under the Creative Commons Attribution International License (CC BY).

http://creativecommons.org/licenses/by/4.0/

(c) () Open Access

\section{Abstract}

A retrospective review was made of intraoperative femoral fracture prevalence in seventy nine consecutive, cementless, fully HA-coated stems used for revision hip arthroplasty. Three patients were lost to follow up. Intraoperative fracture occurred in $15(20 \%)$ femurs. Fractures occurred during cement removal $(3 / 15)$ or insertion of the implant $(12 / 15)$. All fractures were identified using intraoperative biplane $X$-ray, and were treated during the same operation. The clinical outcome of both groups (with or without fractures) was similar. The risk of intraoperative fracture was not statistically related to any demographic features or operative technique. Intraoperative radiographs are therefore mandatory in revision hip arthroplasty in order to diagnose and treat the common complication of femur fracture appropriately.

\section{Keywords}

Revision Hip Arthroplasty; Intraoperative Fracture; Fully Coated HA Stem; Femoral Periprosthetic Fracture

\section{Introduction}

The increased number of total hip replacements performed during the last two decades has inevitably made revision surgery more common. Revision hip arthroplasty has a higher rate of complication than primary surgery [1].

${ }^{*}$ Corresponding author.

How to cite this paper: Rothem, D.E., Rothem, L., Lerner, A., Salamon, T., Hiscock, R. and Bergman, N. (2014) Intraoperative Fracture of the Femur in Revision Total Hip Arthroplasty with a Fully HA-Coated Stem. Open Journal of Orthopedics, 4, 70-76. http://dx.doi.org/10.4236/ojo.2014.43012 
Femoral reconstruction can be extremely challenging. The goal in femoral reconstruction during revision hip arthroplasty is to achieve good implant fixation despite bone defects, poor bone quality and variable canal size. In order to overcome these obstacles for fixation, several options are available. This includes modular stems and bodies with a variety of lengths and diameters, degree and type of coating, plus geometries of the stem. Intraoperative fracture during revision hip arthroplasty is a well-recognized complication. Contributing patient features and technical factors has been identified [2]-[8]. The incidence of intraoperative fracture, using cementless revision implants, is $1 \%$ to $46 \%$ (Table 1 ) [9]-[15].

The aim of this study was to assess the prevalence of intraoperative femur fracture using a cementless fully coated HA stem utilizing intraoperative radiographs taken in two planes after insertion of the stem. Additionally, we retrospectively reviewed the patients' chart and radiographs in order to correlate risk factors associated with intraoperative fractures and the effect of the fracture on the outcomes.

\section{Material and Methods}

79 consecutive revision hip arthroplasties in which an uncemented stem was used in 70 patients, performed between October 1995 and August 2009, were reviewed. In each case the Restoration Hip Stem (Stryker, Mahwah, NJ), was implanted. The cylindrical plasma HA fully coated stem was used. Three patients were excluded as they were lost to follow-up or their radiographs were not available, leaving 67 patients with 76 hips in the study group. 69 stems, 91\%, were straight. 7 stems (9\%) were bowed. Forty four out of 76 (58\%) revision hip arthroplasties received non-modular Restoration stems and 34 (42\%) received modular Restoration stems. All cases were performed by the senior author at one institution (Warringal Private Hospital, Heidelberg, Australia) (Table 2). The 76 revision hip arthroplasties were in 67 patients (34 female, 33 male). The mean follow-up time was 6.3 years (range of 1.8 - 15.2 years). All cases were included to determine the prevalence of an intraoperative fracture.

The indication for femoral revision was aseptic loosening in 60 hips, second stage reimplantation for infection in 10 hips, non-union or malunion of an intertrochanteric fracture in 3 hips, periprosthetic fracture in 2 hips and short leg post primary hip arthroplasty in 1 hip (Table 2). There was a mean of 1.3 previous surgeries (range 1 5) (Table 2). Forty of the stems revised were cemented, 33 were uncemented stems and 3 required removal of a sliding hip screw (Table 2). All Cases were templated preoperatively to determine the stem diameter that would achieve the best fit. The final stem diameter was decided during canal preparation. A posterolateral approach without femoral osteotomy was used in 26 hips, and in 50 hips a femoral osteotomy was incorporated to facilitate removal of the stem and cement. The femoral canals were under-reamed by $0.5 \mathrm{~mm}$.

Patient charts and postoperative radiographs were reviewed by an independent observer (D.R.) who did not participate in any of the operative procedures.

Descriptive data is presented as mean (SD), median $\left[25^{\text {th }}-75^{\text {th }}\right.$ percentile] or count (\%), according to type \& distribution. Eight covariates were transformed prior to regression modeling, with the baseline for BMI set at 20 $\mathrm{kg} \cdot \mathrm{m}^{-2}$ whilst age, blood loss, surgical time, intramedullary reaming diameter, stem diameter, length and shape were set at their respective means or values close to the mean. The unit of change for odds ratio is as presented except for age (5 year), BMI (5 unit), blood loss $(250 \mathrm{ml})$ and surgical time (60 minutes). Whilst improving model stability and allowing meaningful interpretation of regression coefficients, these transformations do not

Table 1. Prevalence of intraoperative fracture.

\begin{tabular}{|c|c|c|c|}
\hline Author & Hips & Intraoperative Fractures & Stem Type \\
\hline Egan et al. [7] & 135 & $27(20 \%)$ & Fully porous-coated straight stem \\
\hline Malkani et al. [12] & 175 & $34(46 \%)$ & Proximally coated, bowed long stem \\
\hline Paprosky et al. [18] & 170 & $15(9 \%)$ & Fully porous-coated straight stem \\
\hline Zalzal et al. [19] & 45 & $7(17.5 \%)$ & Straight, 205-mm fully coated \\
\hline Meek et al. [20] & 211 & $64(30 \%)$ & Fully porous-coated stem (135 bowed, 76 straight) \\
\hline Chappell et al. [21] & 54 & $8(15 \%)$ & Fully porous-coated stem (50 bowed, 4 straight) \\
\hline Present study & 76 & $15(20 \%)$ & Cylindrical plasma HA fully coated (7 bowed, 69 straight) \\
\hline
\end{tabular}


Table 2. Patient demographics and preoperative data.

\begin{tabular}{cc}
\hline Patient Demographics (Patient No. = 67, Hips No. = 76) & Number of Patients or Average (Range) \\
Age (Years) & $72(20-91)$ \\
Gender & 33 \\
Male & 34 \\
Female & $29.8(20.3-42.8)$ \\
BMI (kg/m $\left.{ }^{2}\right)$ & \\
Diagnosis & 60 \\
Aseptic Loosening & 10 \\
Infected Total Hip & 3 \\
Periprosthetic Fracture & 2 \\
Short Leg Post THR & 1 \\
Previous Surgeries & $1.3(1-5)$ \\
Fon-Union and/or Malunion of Intertrochanteric Fracture & $40 / 33 / 3$ \\
Revised Stem Type (Cemented/Cementless/DHS) & $6.3(1.8-15.2)$ \\
\hline
\end{tabular}

change statistical inference. For the dichotomous variables stem length, stem shape and stem type the categories are $167 \mathrm{~mm} / 205 \mathrm{~mm}$, straight/bowed and HA modular/HA non-modular respectively.

Univariable logistic regression was used to assess association between intraoperative femoral fracture and measured covariates. Multivariable logistic regression was then performed and included all covariates where likelihood ratio chi-squared in the univariable logistic regression had $p$-values $\leq 0.2$. Regression diagnostics were performed. Significance level was set at 0.05. Analysis was performed using Stata v11 software (StataCorp. 2009. Stata Statistical Software: Release 11. College Station, TX: StataCorp LP).

\section{Results}

The prevalence of intraoperative fracture of the femur was fifteen (20\%) of the seventy-six femoral component revisions. The remaining sixty-one (80\%) had no fracture (control group). There was no significant differences in age $(p=0.89)$, gender $(p=0.95)$, BMI $(p=0.18)$, previous surgeries $(p=0.26)$, revised stem type $(p=0.99)$ (Table 2). Likewise, unvariable logistic regression of operative data variables (i.e. operation time, blood loss, approach) (Table 3) against the occurrence of femoral fracture was performed with the odds ratio and associated $p$-value. No statistical significance was found. In addition, there was no association among the prevalence of fracture and intraoperative reaming diameter, stem size, diameter or length $(p>0.1)$ (Tables 3 and 4$)$.

There was no significant difference in fracture rate between the bowed and straight stems: 4 (7\%) of the 61 stems were bowed in the control group compared with $3(20 \%)$ of the 15 stems were bowed in the intraoperative fracture group ( $p=0.12$ ) (Table 4). A posterior approach was used in all 76 revision hip arthroplasties with or without osteotomy, neither approach was found to be associated with an intraoperative fracture $(p=0.20)$ (Table 4). There was no significant association between the prevalence of intraoperative fracture and preoperative diagnosis.

The most frequent intraoperative fracture occurred during insertion of the component. 12 (16\%) out of 15 intraoperative fractures. Three (4\%) fractures of the femur occurred during cement removal (Table 5). Fracture occurring during cement removal or insertion of the implant was B1, according to the Vancouver classification [16]. All the intraoperative fractures were diagnosed with an intraoperative X-ray (AP and lateral) taken immediately after the insertion of the femoral stem (Figure 1). Patients with an intraoperative canal perforation and/or fracture prior to stem insertion ( 3 out of 15 patients), were treated by allograft strut or morsellized bone and cables. However, the 12 patients with intraoperative fractures that occurred during the insertion of the compo- 
Table 3. Patient demographics and preoperative data.

\begin{tabular}{|c|c|c|c|c|}
\hline \multirow{2}{*}{ Parameters } & \multicolumn{4}{|c|}{ Number of Patient or Average (Range or Percentage) } \\
\hline & Without Femoral Fracture & Femoral Fracture & Odds Ratio* (95\% CI OR) & $P$-value \\
\hline Age (yrs) & $73( \pm 12.6)$ & $72( \pm 14)$ & $0.99(0.79-1.22)$ & 0.89 \\
\hline Gender (male) & $29(48 \%)$ & $7(47 \%)$ & $0.97(0.31-3.0)$ & 0.95 \\
\hline BMI $\left(\mathrm{kg} \cdot \mathrm{m}^{-2}\right)$ & $30( \pm 5.7)$ & $28( \pm 4.4)$ & $0.64(0.33-1.23)$ & 0.18 \\
\hline \multicolumn{5}{|l|}{ Previous Surgery } \\
\hline 1 & $49(86 \%)$ & $10(67 \%)$ & 1 & 0.26 \\
\hline 2 & $5(9 \%)$ & $3(20 \%)$ & $2.94[0.6-14.34]$ & NA \\
\hline 3 & $3(5 \%)$ & $2(13 \%)$ & $3.27[0.48-22.15]$ & NA \\
\hline Revised Stem Type Cementless & $26(43 \%)$ & $7(47 \%)$ & 1 & 0.99 \\
\hline Cemented & 32 (52\%) & 8 (53\%) & $0.93[0.26-3.45]$ & NA \\
\hline DHS & $3(5 \%)$ & 0 & $1.04[0.0$ - 10.68] & NA \\
\hline
\end{tabular}

Data presented as mean (SD), median [ $25^{\text {th }}-75^{\text {th }}$ percentile] or count (\%). NA—Not Applicable. ${ }^{*}$ Unit of change as presented except for age (5 years), BMI (5 unit).

Table 4. Operative data with or without femoral fracture.

\begin{tabular}{|c|c|c|c|c|}
\hline Parameters & $\begin{array}{c}\text { Intraoperative without Femoral } \\
\text { Fracture (Hip No. 61) }\end{array}$ & $\begin{array}{l}\text { Intraoperative Femoral } \\
\text { Fracture (Hip No. 15) }\end{array}$ & $\begin{array}{l}\text { Odds Ratio* } \\
\text { (95\% CI OR) }\end{array}$ & $P$-value \\
\hline Operation Time (min) & $281( \pm 77)$ & $260( \pm 58)$ & $0.78[0.48-1.26]$ & 0.31 \\
\hline Blood Loss (cc) & $1200[800-1800]$ & $1000[700-1200]$ & $0.86[0.68-1.09]$ & 0.21 \\
\hline $\begin{array}{l}\text { Posterolateral Approach } \\
\text { with Osteotomy }\end{array}$ & 20 (33\%) & $6(40 \%)$ & $0.20[0.03-1.18]$ & 0.20 \\
\hline $\begin{array}{l}\text { Posterolateral Approach } \\
\text { without Osteotomy }\end{array}$ & $41(67 \%)$ & $9(60 \%)$ & $0.40[0.07-2.31]$ & 0.20 \\
\hline $\begin{array}{c}\text { Intramedullary } \\
\text { Reaming Diameter }\end{array}$ & $16.5(13.5-22.5)$ & $17(14-19.5)$ & $1.04[0.80-1.36]$ & 0.78 \\
\hline Stem Diameter & $17(14-23)$ & $17(15-20)$ & $1.03[0.79-1.34]$ & 0.83 \\
\hline $\begin{array}{c}\text { Stem length } \\
167 \mathrm{~mm} / \mathbf{2 0 5} \mathbf{~ m m}^{* *}\end{array}$ & 27 (44\%)/34 (56\%) & $6(40 \%) / 9(60 \%)$ & $1.10[0.86-1.40]$ & 0.44 \\
\hline $\begin{array}{c}\text { Stem Shape } \\
\text { Bowed }^{* *} / \text { Straight }\end{array}$ & 4 (6.5\%)/57 (93.5\%) & $3(20 \%) / 12(80 \%)$ & $3.56[0.70-18.02]$ & 0.12 \\
\hline $\begin{array}{c}\text { Stem Type } \\
\text { HA modular }{ }^{* *} \text { non-modular }\end{array}$ & $25(43 \%) / 36(57.5 \%)$ & 7 (58\%)/8 (42\%) & $1.85[0.52-6.51]$ & 0.34 \\
\hline
\end{tabular}

Data presented as mean (SD), median $\left[25^{\text {th }}-75^{\text {th }}\right.$ percentile $]$ or count $(\%) .{ }^{*}$ Unit of change as presented. ${ }^{* *}$ In bold-for the dichotomous variables stem length, stem shape and stem type the categories are $167 \mathrm{~mm} / 205 \mathrm{~mm}$, straight/bowed and HA modular/HA non-modular respectively.

nent were treated by cable reinforcement alone and allowed to weight bear as tolerated. All fractures united with good clinical outcome.

For the 61 patients without an intraoperative femoral fracture, there was improvement in the postoperative Harris hip score, from a mean of 45 preoperatively to a mean of 65 points at a minimum of 2.3 years of followup. Similarly, the improvement in the Harris hip score for the 15 patients with an intraoperative femoral fracture with a follow-up of 1.8 years or more was from a mean of 45 to 66 points. 
Table 5. Intraoperative femoral fracture.

\begin{tabular}{cccccc}
\hline $\begin{array}{c}\text { Hips } \\
\text { Number }\end{array}$ & Cause of Fracture & $\begin{array}{c}\text { Preoperative } \\
\text { Diagnosis }\end{array}$ & $\begin{array}{c}\text { Classification } \\
\text { of Fracture }\end{array}$ & Treatment & Weight Bearing \\
\hline 3 & $\begin{array}{c}\text { Perforation during } \\
\text { cement removal }\end{array}$ & Aseptic Loosening (3/3) & B1 & $\begin{array}{c}\text { Strut graft } \\
\text { and cables }\end{array}$ & $\begin{array}{c}\text { Partial weight } \\
\text { bearing (6/52) }\end{array}$ \\
\hline 12 & $\begin{array}{c}\text { Insertion of } \\
\text { the implant }\end{array}$ & $\begin{array}{c}\text { Aseptic Loosening }(11 / 12) \\
\text { Infection }(1 / 12)\end{array}$ & B1 & Cables & Weight bearing \\
as tolerated & Union \\
\hline
\end{tabular}

*According to Vancouver classification.

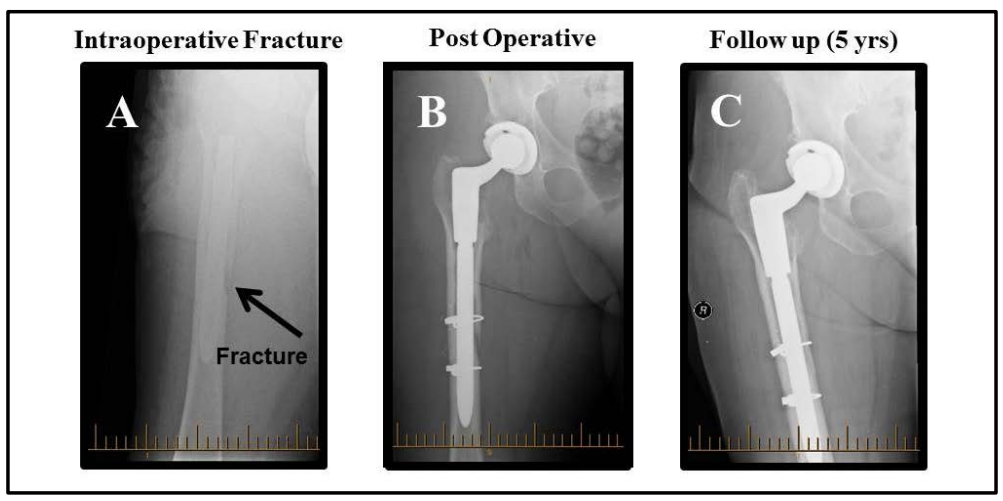

Figure 1. Radiographs of intraoperative fracture during insertion of the stem. A: Intraoperative X-ray after insertion of the stem demonstrates fracture of the femur, B: Postoperative X-ray after treatment of the femoral fracture with cables, C: X-ray after six years follow-up demonstrates united fracture.

\section{Discussion}

The fixation of the femoral component in revision hip arthroplasty is challenging. Recent reports reflect the common usage of cementless femoral components [10] [12] [15] [17] [18]. Previous studies demonstrated that an intraoperative fracture of the femur occurs with exposure, during cement removal, or while inserting the new femoral component [7] [9] [10] [12] [15] [17]-[19]. The most common time during revision surgery for an intraoperative fracture to occur, with cementless implants, is while obtain a tight "scratch fit" at stem insertion. The prevalence of intraoperative fracture of the femur using cementless revision implants is $1 \%$ to $46 \%$ in revision arthroplasty. The majority of studies report, however, that the incidence is less that 15\% (Table 1) [8]-[14]. Malkani et al., reported the highest prevalence of intraoperative fracture of the femur with 34 out of 69 intraoperative fractures (46\%) [12]. Nineteen of the fractures extended below the lesser trochanter and 15 were proximal to the lesser trochanter. Engh et al., reported 3 intraoperative fractures at the tip of the prosthesis out of 21 hips (15\%) [13]. Paprosky et al., reported 8.8\% intraoperative fracture occurring during 187 femoral revisions using straight fully porous-coated stems [18]. These authors stated that there is an association between stem diameter $(\geq 18-\mathrm{mm})$ and stem length $(\geq 205-\mathrm{mm})$ with intraoperative fracture [18]. Zalzal et al., reported intraoperative fracture of the distal femur in $17.5 \%$. They suggested that a straight $205-\mathrm{mm}$, press-fit stem should be used with caution, and a bowed stem of that length should be considered [19]. Meek et al., showed that $30 \%$ of the patients sustained an intraoperative fracture [20]. Their results pointed that the degree of preoperative bone loss and low cortex to canal ratio are risk factors of intraoperative femoral fracture [20].

Intraoperative fractures can occur for a variety of reasons. These include poor preoperative bone quality, length of implant, perforation during cement removal, the reaming technique or during insertion of the component. In the current study we examined the association of multiple preoperative and intraoperative factors with the prevalence of intraoperative fracture. Our results demonstrated that none of the analyzed parameters reached statistical significance. This means that none of the analyzed parameters were a risk factor for intraoperative fracture. This is in contrast to previous studies. 


\section{Conclusion}

In conclusion, the results of the current study suggest that despite preoperative templating and careful insertion of the implant, there is high prevalence of intraoperative fracture. Thus, the senior author always obtains an intraoperative radiograph without breaking sterility. Our results confirm that immediate diagnosis and treatment of the intraoperative fractures leads to the same clinical outcome as those hips without intraoperative fracture.

\section{References}

[1] Dupont, J.A. and Charnley, J. (1972) Low-Friction Arthroplasty of the Hip for the Failures of Previous Operations. Journal of Bone Joint Surgery Br., 54, 77-87.

[2] Federici, A., Carbone, M. and Sanguineti, F. (1988) Intraoperative Fractures of the Femoral Diaphysis in Hip Arthroprosthesis Surgery. Journal of Orthopaedics and Traumatology, 14, 311-321.

[3] Haddad, F.S., Masri, B.A., Garbuz, D.S. and Duncan, C.P. (1999) The Prevention of Periprosthetic Fractures in Total Hip and Knee Arthroplasty. Orthopedic Clinics of North America, 30, 191-207. http://dx.doi.org/10.1016/S0030-5898(05)70074-2

[4] Terzi, S., Toni, A., Zanotli Russo, M.C., Nardi, D., Sudanese, A. and Giunti, A. (1997) Intraoperative Fracture of the Femur in Prosthetic Hip Reimplantations. La Chirurgia degli Organi di Movimento, 82, 221-230.

[5] Wu, C.C., Au, M.K., Wu, S.S. and Lin, L.C. (1999) Risk Factors for Postoperative Femoral Fracture Incementless Hip Arthroplasty. Journal of the Formosan Medical Association, 98, 190-194.

[6] Toni, A., Ciaroni, D., Sudanese, A., Femino, F., Marraro, M.D., Bueno Lozano, A.L. and Giunti, A. (1994) Incidence of Intraoperative Femoral Fracture. Straight-Stemmed versus Anatomiccementless Total Hip Arthroplasty. Acta Orthopaedica Belgica, 60, 43-54.

[7] Egan, K.J. and Dicesare, P.E. (1995) Intraoperative Complications of Revision Hip Arthroplasty Using a Fully PorousCoated Straight Cobalt-Chrome Femoral Stem. Journal of Arthroplasty, 10, S45-S51. http://dx.doi.org/10.1016/S0883-5403(05)80230-X

[8] Fitzgerald Jr., R.H., Brindley, G.W. and Kavanagh, B.F. (1988) The Uncemented Total Hip Arthroplasty. Intraoperative Femoral Fractures. Clinical Orthopaedics, 235, 61-66.

[9] Gustilo, R.B. and Pasternak, H.S. (1988) Revision Total Hip Arthroplasty with Titanium Ingrowth Prosthesis and Bone Grafting for Failed Cemented Femoral Component Loosening. Clinical Orthopaedics and Related Research, 235, 111119.

[10] Lawrence, J.M., Engh, C.A., Macalino, G.E. and Lauro, G.R. (1994) Outcome of Revision Hip Arthroplasty Done without Cement. The Journal of Bone \& Joint Surgery, 76A, 965-973.

[11] Moreland, J.R. and Bernstein, M.L. (1995) Femoral Revision Hip Arthroplasty with Uncemented, Porous-Coated Stems. Clinical Orthopaedics and Related Research, 319, 141-150.

[12] Malkani, A.L., Lewallen, D.G., Cabanela, M.E. and Wallrichs, S.L. (1996) Femoral Component Revision Using an Uncemented, Proximally Coated, Long-Stem Prosthesis. Journal of Arthroplasty, 11, 411-418. http://dx.doi.org/10.1016/S0883-5403(96)80031-3

[13] Engh, C.A., Culpepper, W.J. and Kassapidis, E. (1998) Revision of Loose Cementless Femoral Prostheses to Larger Porous Coated Components. Clinical Orthopaedics and Related Research, 347, 168-178. http://dx.doi.org/10.1097/00003086-199802000-00019

[14] Aribindi, R., Barba, M., Solomon, M.I., Arp, P. and Paprosky, W. (1998) Bypass Fixation. Orthopedic Clinics of North America, 29, 319-329. http://dx.doi.org/10.1016/S0030-5898(05)70330-8

[15] Krishnamurthy, A.B., MacDonald, S.J. and Paprosky, W.G. (1997) 5- to 13-Year Follow-Up Study on Cementless Femoral Components in Revision Surgery. Journal of Arthroplasty, 12, 839-847. http://dx.doi.org/10.1016/S0883-5403(97)90152-2

[16] Younger, T.I., Bradford, M.S., Magnus, R.E. and Paprosky, W.G. (1995) Extended Proximal Femoral Osteotomy. A New Technique for Femoral Revision Arthroplasty. Journal of Arthroplasty, 10, 329-338. http://dx.doi.org/10.1016/S0883-5403(05)80182-2

[17] Engh, C.A., Glassman, A.H., Griffin, W.L. and Mayer, J.G. (1988) Results of Cementless Revision for Failed Cemented Total Hip Arthroplasty. Clinical Orthopaedics, 235, 91-110.

[18] Praprosky, W.G., Greidanus, N.V. and Antoniou, J. (1999) Minimum 10 Year Results of Extensively Porous-Coated Stems in Revision Hip Arthroplasty. Clinical Orthopaedics, 369, 230. http://dx.doi.org/10.1097/00003086-199912000-00024

[19] Zalzal, R., Gandi, R., Petruccelli, D., Petruccelli, D., Winemaker, M.J. and de Beer, J. (2003) Fractures at the Tip of 
Long-Stem Prostheses Used for Revision Hip Arthroplasty. Journal of Arthroplasty, 18, 741-745. http://dx.doi.org/10.1016/S0883-5403(03)00258-4

[20] Meek, R.M., Garbuz, D.S., Masri, B.A., Greidanus, N.V. and Duncan, C.P. (2004) Intraoperative Fracture of the Femur in Revision Total Hip Arthroplasty with a Diaphyseal Fitting Stem. The Journal of Bone \& Joint Surgery, 86, 480-485.

[21] Chappell, J.D. and Lachiewicz, M.D. (2005) Fracture of the Femur in Revision Hip Arthroplasty with a Fully PorousCoated Component. Journal of Arthroplasty, 20, 234-238. http://dx.doi.org/10.1016/j.arth.2004.10.013 